\title{
Developing Nutrient Criteria/TMDLs to Manage Excessive Fertilization of Waterbodies*
}

\author{
G. Fred Lee, Ph D, PE, DEE Anne Jones-Lee, PhD \\ G. Fred Lee \& Associates \\ 27298 E. El Macero Dr. \\ El Macero, CA 95618 \\ 530-753-9630ｇfredlee@aol.com www.gfredlee.com
}

\begin{abstract}
Excessive fertilization is one of the most common and significant causes of the impairment of the beneficial uses of waterbodies. As a result of the widespread occurrence of excessive fertilization of waterbodies, the US EPA has initiated development of chemical-specific (nitrogen and phosphorus compounds) numeric water quality criteria designed to be the basis of control of the excessive fertilization of waterbodies. These criteria will be used to establish state water quality standards, where exceedance of the standard will be used to designate Clean Water Act 303(d) "impaired" waterbodies that will lead to the need to implement a TMDL to achieve the nutrient water quality standard. The Agency has established 2004 as a date by which state regulatory agencies must have made significant progress toward adopting chemical-specific nutrient criteria/standards. This means that, by the mid 2000s, there could be a large number of additional waterbodies, beyond those already classified as nutrient-impaired, that need to have TMDLs developed and implemented in order to satisfy nutrient control requirements.
\end{abstract}

The US EPA has adopted two approaches for developing nutrient water quality criteria/standards. One of these is the Agency's "default" approach, where emphasis is on assessing the pre-cultural nutrient concentrations in a waterbody as a basis for establishing the allowable nutrient concentrations. If no non-culturally impacted (no urban or agriculture activities occur in the watershed) representative reference waterbodies are available in the area, the Agency proposes to use the 25th percentile of the existing nutrient concentrations for current total $\mathrm{P}$ and total $\mathrm{N}$ including organic nitrogen as the criterion/standard value. Adopting this default approach means that 75 percent of the waterbodies in a region would violate the nutrient criterion/standard and therefore be subject to nutrient TMDL development. The US EPA's proposed approach for developing default nutrient criterion is recognized by many who are familiar with how nutrients impact water quality as technically invalid. It ignores the large amounts of high quality information that was developed in the1960s and '70s on how nutrients impact water quality and how fertility of a waterbody impacts its beneficial uses. The Agency's approach could result in massive expenditures for nutrient control from point and non-point sources beyond that needed to achieve the desired nutrient-related beneficial uses of a waterbody. Further, this approach could be significantly detrimental to the aquatic life (fisheries)-related beneficial uses of a waterbody as a result of adversely impacting the trophic structure of waterbodies.

* Proceedings Water Environment Federation, TMDL 2002 Conference, Phoenix, AZ, November (2002) 
The Agency's other proposed approach for developing nutrient criteria/standards potentially involves the regulatory Agencies and the regulated community, as well as others interested, working together to develop site-specific nutrient criteria/standards for a waterbody or group of similar waterbodies. According to the US EPA, the site-specific criterion development approach must be "scientifically defensible." The Agency; however, does not define what that means. This paper discusses recommended approaches for developing site-specific nutrient criteria that will protect the nutrient impact-related beneficial uses of a waterbody, without significant unnecessary expenditures for nutrient control. Particular attention is given to developing a sitespecific stakeholder assessment of the desired nutrient-related water quality in a waterbody(s), and site-specific nutrient load eutrophication response relationships for the waterbody that can be used to determine the degree of nutrient control needed to achieve the desired nutrient-related water quality in the waterbody. In addition to being applicable to developing site-specific nutrient criteria, the issues discussed in this paper are also applicable to developing appropriate nutrient-related TMDL goals. This paper is based on 42 years of the author's experience in investigating and managing excessive fertilization of waterbodies in the US and many other countries. Background information on these issues is provided on the author's website, www.gfredlee.com.

KEYWORDS Excessive fertilization, nutrients, TMDLs, nutrient criteria, eutrophication, nitrogen, phosphorus

\section{INTRODUCTION}

Increasing attention is being given to controlling the water quality impacts associated with excessive fertilization (eutrophication) of waterbodies. This effort is leading to increased attention to the role of urban and agricultural stormwater runoff/discharges as a source of aquatic plant nutrients (nitrogen and phosphorus compounds) that cause excessive fertilization of waterbodies. In order to better control excessive fertilization of the nation's waters, the US EPA and the states are developing nutrient (nitrogen and phosphorus) based numeric water quality criteria that will be used to serve as the goal for nutrient control programs. The paper presents a review of some of the issues that need to be considered in developing nutrient based water quality criteria and their appropriate use in controlling excessive fertilization of waterbodies in TMDLs.

\section{WATER QUALITY IMPACTS OF WATERBODY EXCESSIVE FERTILIZATION}

The excessive fertilization of waterbodies is a long-standing, well-recognized cause of water quality problems throughout the US and other countries. It is manifested in excessive growths of planktonic (suspended) algae and attached algae, as well as macrophytes (water weeds), which either can be floating, such as water hyacinth or duckweed, or be attached-emergent. The impacts of excessive fertilization-eutrophication on a waterbody's water quality were discussed by Lee (1971). A brief summary of water quality problems caused by excessive fertilization which can lead to a 303(d) listing of a waterbody as "impaired" is presented below. 


\section{Domestic Water Supplies}

Planktonic algae can have a severe impact on domestic water supply water quality through shortened filter runs, the release of organic compounds that cause tastes and odors, and, in some instances, the production of trihalomethane (THM) precursors. The THMs are chloroform and chloroform-like compounds which are formed during the disinfection of water supplies. They are regulated as human carcinogens. Excessive fertilization of a water utility's water supply leads to increased cost of treatment.

\section{Violations of Water Quality Standards}

The excessive fertilization of waterbodies can lead to marked diel (night to day) changes in $\mathrm{pH}$ and dissolved oxygen concentrations. The diel photosynthesis/respiratory changes are the result of algal removal of $\mathrm{CO}_{2}$ from the water, which, by late afternoon, can cause the $\mathrm{pH}$ of the water to increase above the water quality standard. Accompanying algal growth, which occurs in light, there is production of oxygen. However, in the dark, the algae and other organisms in the water are only respiring, which results in the release of $\mathrm{CO}_{2}$, lowering the $\mathrm{pH}$, with a concomitant consumption of oxygen. The dissolved oxygen in a waterbody just before sunrise can be sufficiently low to violate water quality standards for protection of fish and other aquatic life. Richards (1965) has shown that one phosphorus atom, when converted to an algal cell which subsequently dies, can consume 276 oxygen atoms as part of the decay process.

While, ordinarily, the DO depletion issue is a near-bottom water issue, where there is thermal stratification which inhibits the surface water oxygen produced by planktonic algae and aeration from mixing to the bottom, there are situations where the algal-related oxygen demand can be sufficient (such as in the San Joaquin River Deep Water Ship Channel near Stockton, California) to cause DO depletion problems in the surface waters as well (see Lee and Jones-Lee, 2000, 2001, 2002) .

Figure 1 presents a diagram which shows the DO depletion issues in the San Joaquin River (SJR) Deep Water Ship Channel (DWSC). The SJR just upstream of the DWSC is eight to 10 feet deep and does not experience DO depletion problems. Upon entry into the 35-foot-deep DWSC, the oxygen demand in the form of algae and other constituents in the SJR begins to be exerted at a rate which greatly exceeds the oxygen production by the algae in the upper approximately one meter of water with sufficient light to support algal growth, as well as aeration from the atmosphere. This leads to significant DO depletion problems throughout the water column. The reactions/processes involved are shown in Figure 2.

\section{Toxic Algae}

One of the major stimuli for increased US EPA attention to excessive fertilization is the Pfiesteria problem in Chesapeake Bay (US EPA 2000a), where fish kills have occurred due to the presence of toxic algae. Fish kills associated with toxic algae are not new; they have been occurring in various waterbodies around the world for many years. Further, blue-green algae at times excrete toxins which are known to kill livestock and other animals. 
Figure 1-DO Depletion Processes in the San Joaquin River Ship Channel

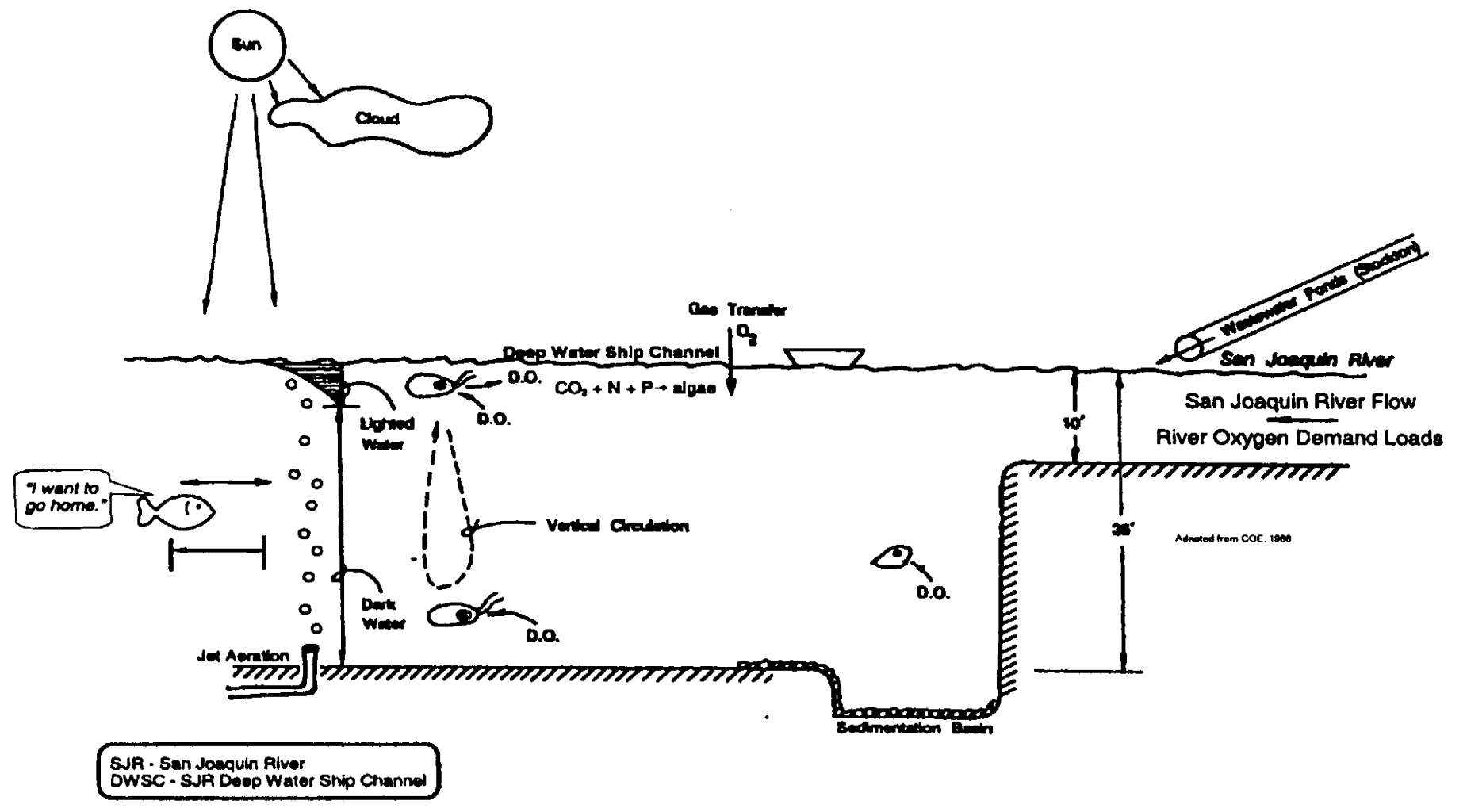

\section{Issues in Developing the San Joaquin River Deep Water Ship Channel DO TMDL}

From Lee and Jones-Lee (2000).

\section{Impaired Recreation}

Excessive growth of algae, both planktonic and attached, can affect the use of waterbodies for swimming, boating and fishing through interference with water contact. They can also lead to severe odor problems due to decaying algae, algal scums, etc. 
Figure 2- DO Depletion Reactions in the SJR DWSC

\section{Algae \& Organic Detritus as Sources of Oxygen Demand}

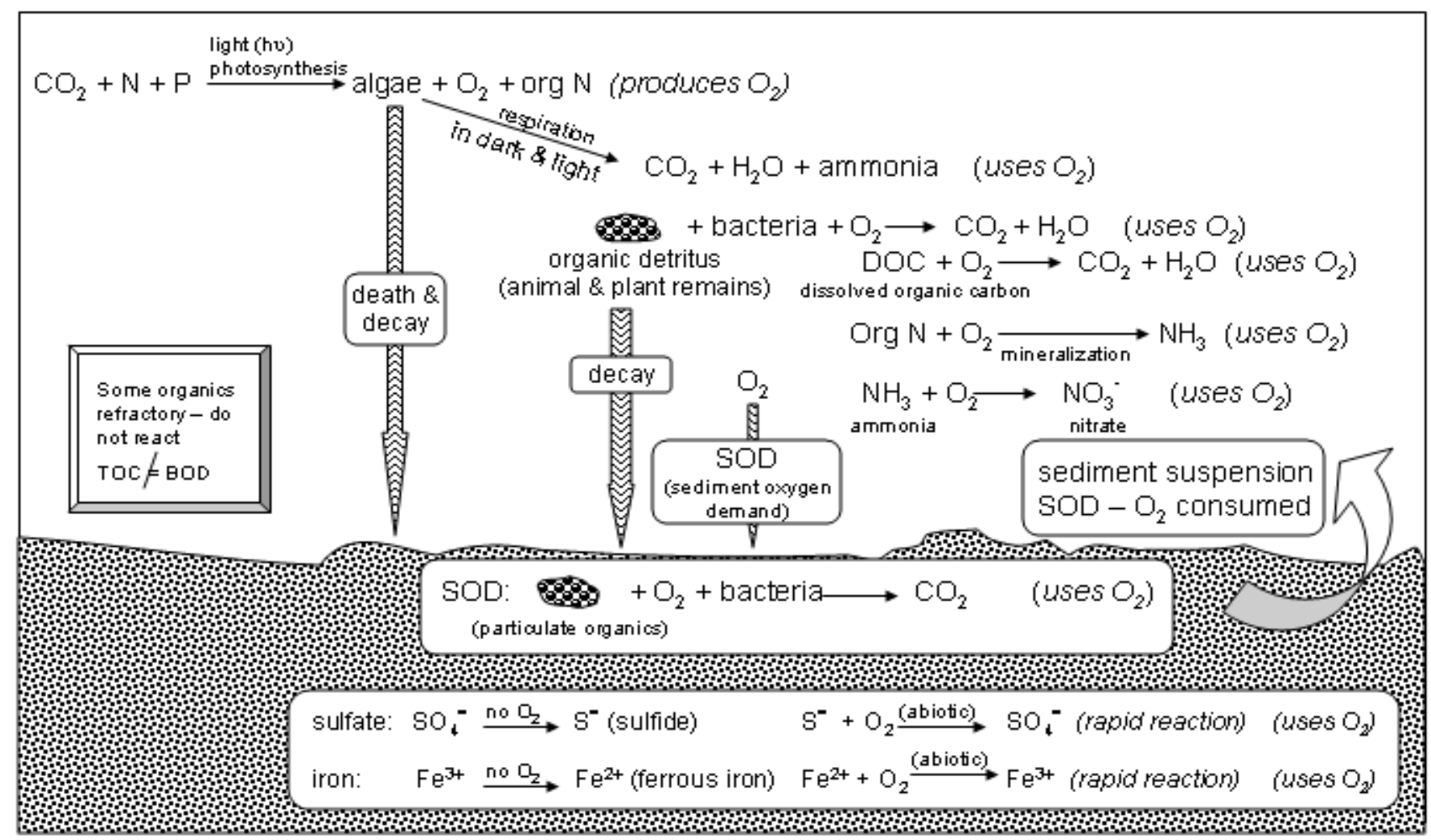

From Lee and Jones-Lee (2000).

\section{Impact on Fisheries}

Fertilization of waterbodies improves fish production in terms of total biomass; however, as Lee and Jones (1991) discuss, it can be adverse to production of desirable forms of fish, especially at high fertilization levels. In waterbodies that stratify, with a cold hypolimnion (bottom waters), oxygen demand created by the growth of algae in the surface waters which die and settle into the hypolimnion can be sufficient to deplete the oxygen. This is a characteristic of highly eutrophic waterbodies. This, in turn, means that, in temperate climates, the coldwater fish (such as the salmonids, trout, etc.) that normally inhabit the hypolimnion cannot survive because of a lack of oxygen. Further, with respect to the increased production in highly eutrophic waterbodies, the populations of rough fish, such as carp, which can tolerate lower dissolved oxygen levels, often dominate the increased production. These relationships are shown in Figure 3. 
Figure 3-Effect of Phosphorus Loads on Fish Production

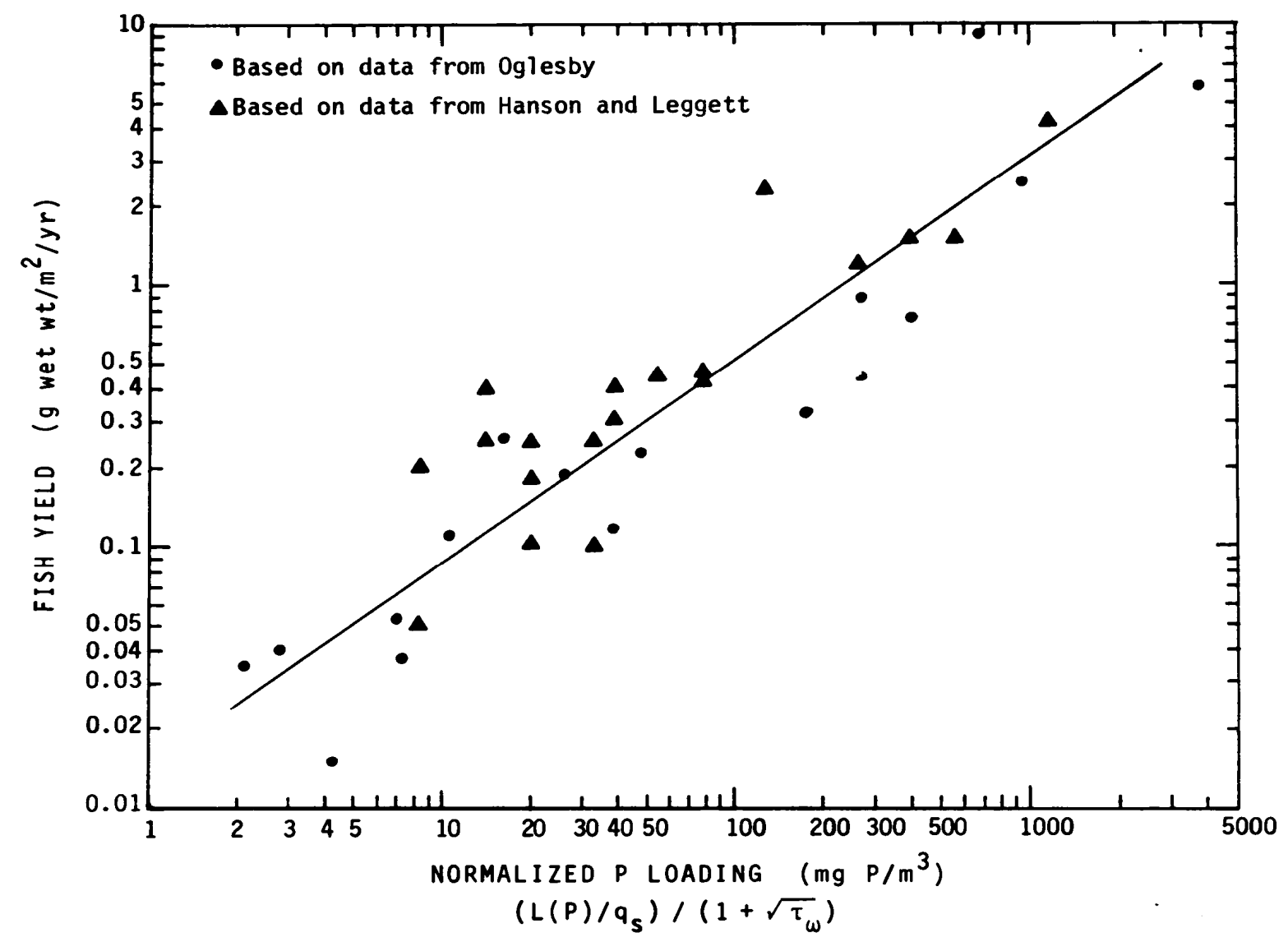

From Lee and Jones (1991)

\section{Shallow Water Habitat}

Emergent aquatic vegetation in the shallow waters of waterbodies provides important habitat for various forms of aquatic life. As discussed by Lee (1971), increased planktonic algal growth in a waterbody reduces light penetration which in turn inhibits the growth of emergent vegetation, resulting in loss of significant aquatic life habitat.

\section{Overall Impacts}

Excessive fertilization is one of the most important causes of water quality impairment of waterbodies. The US EPA (2000a), in its last National Water Quality Inventory, has listed nutrients as the leading cause of water quality impaired lakes and reservoirs. Further, the Agency lists agriculture as the primary source of constituents (nutrients and sediments) that impair lakes. 


\section{NUTRIENTS OF CONCERN}

The nutrients of primary concern are nitrogen and phosphorus compounds. While algae, like other forms of aquatic plants, require a variety of chemical constituents, light, and appropriate temperatures to develop, the primary issue of concern in managing algal populations is the nutrient that is present in the least amount compared to algal needs.

In many highly fertile waterbodies, neither nitrogen nor phosphorus is limiting algal growth. Both are present above growth-rate-limiting concentrations -- i.e., they occur on the plateau of the algal growth-nutrient concentration relationship (see Figure 4). Typically, growth-ratelimiting concentrations for phosphorus are on the order of 2 to $8 \mu \mathrm{g} / \mathrm{L}$ available-P, and for nitrogen are on the order of 15 to $30 \mu \mathrm{g} / \mathrm{L}$ available-N (in the form of nitrate, nitrite and ammonia). It is important to understand that, even at growth-rate-limiting concentrations, appreciable algal biomass can develop if there is sufficient time for algal growth to occur. Lee and Jones-Lee (1998) have discussed the approach that should be used in determining nutrientlimiting algal growth in a waterbody. It is based on determining the concentrations of available nutrients at peak biomass. The typical approach of trying to use Redfield numbers to estimate limiting nutrients is often unreliable.

\section{Figure 4}

\section{Relationship between Nutrient Concentration and Algal Biomass}

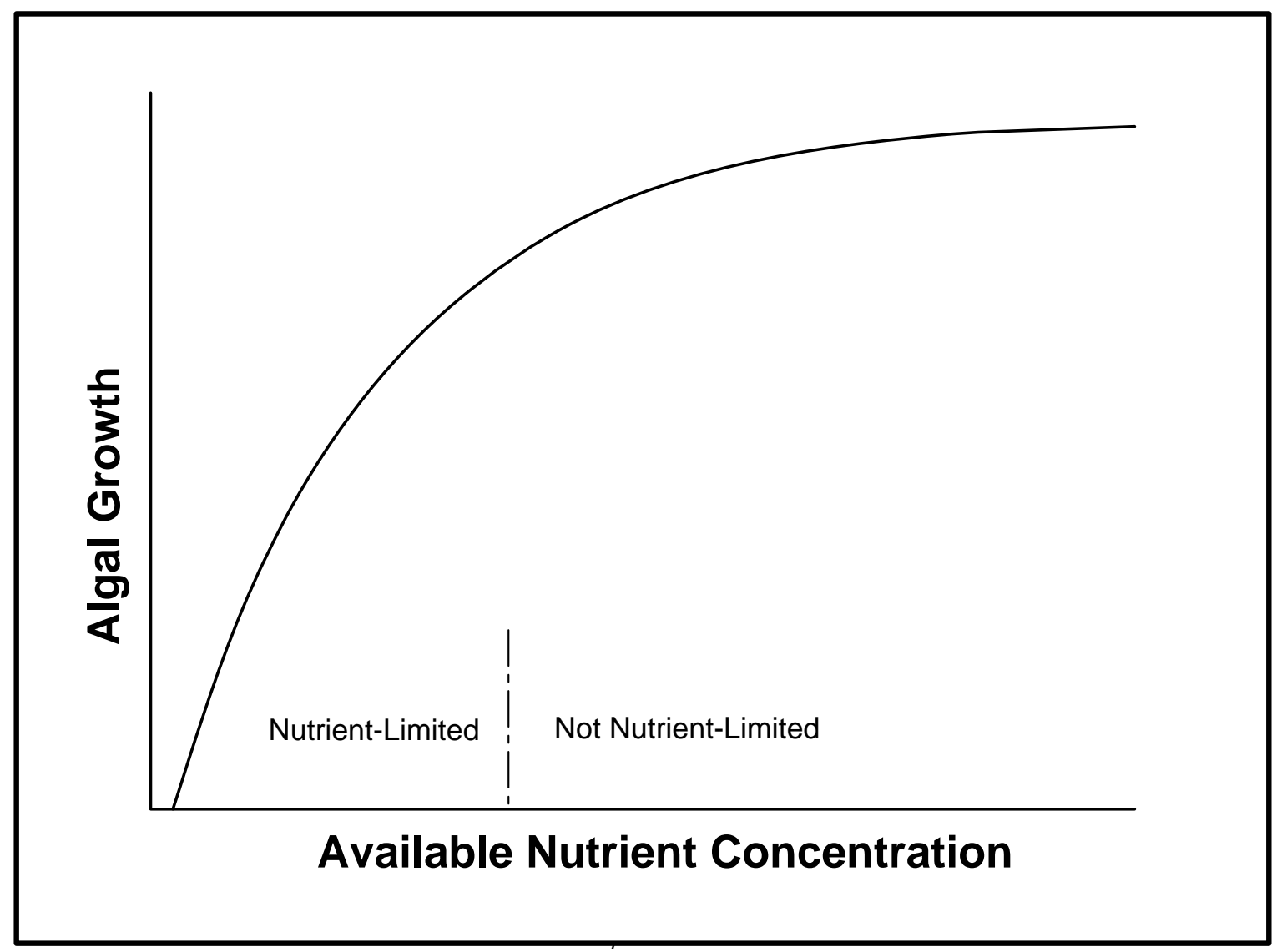


From Lee and Jones-Lee (2000).

\section{TOTAL PHOSPHORUS VERSUS ALGAL-AVAILABLE PHOSPHORUS}

The US EPA (1998), as part of developing nutrient criteria, is focusing on total phosphorus. However, it was well-established many years ago that most of the particulate phosphorus in agricultural and urban stormwater runoff is not available to support algal growth. Lee, et al. (1980) conducted extensive research on this topic, and also published a review of these issues for the International Joint Commission for the Great Lakes. They found, based on their work as well as the work of others, that the algal available $\mathrm{P}$ can be estimated as the soluble ortho-P, plus about 20 percent of the particulate $P$ in agricultural and urban runoff. Algal-available nitrogen can be estimated as the nitrate plus nitrite plus ammonia, and some site-specific fraction of the organic nitrogen. The fraction of the organic nitrogen that is available depends on its source and age.

Part of the problem with the US EPA's approach to properly addressing algal available nutrients in developing nutrient criteria is that the Agency is relying on improper interpretation of radiophosphorus exchange studies. Studies conducted in the 1960s showed that the addition of P-32 to a water sample resulted in some of the dissolved P becoming incorporated into the solid phase and vise versa. Those familiar with radiolabel exchange experiments know that surficial exchanges do not measure available forms of nutrients in the solid phase. Algal growth experiments in which all nutrients needed for algal growth are available in surplus of algal needs except for the $\mathrm{P}$ in the water sample being tested showed that most of the particulate $\mathrm{P}$ in agricultural and urban stormwater runoff from a variety of sources is not available for algal growth. These results are based on both short-term and long-term (one year) incubation. The lack of availability of part of the phosphorus in soils is well known to the agriculture community who find that total $\mathrm{P}$ in soils is not a reliable measure of plant-available $\mathrm{P}$. As discussed by Jones-Lee and Lee (2001) nutrient criteria for regulating agricultural and urban stormwater runoff should be based on soluble orthophosphate and nitrate plus ammonia plus about 20 percent of the particulate $\mathrm{P}$ and $\mathrm{N}$. However, if the source of the $\mathrm{P}$ and $\mathrm{N}$ are algae or organic forms such as manure, then most of the total $\mathrm{N}$ and total $\mathrm{P}$ can be mineralized and in time will become available to support algal growth.

Focusing nutrient control programs on available forms of phosphorus is important in selecting and evaluation of nutrient runoff BMPs. At this time most of the agricultural BMPs focus on the control of particulate $\mathrm{P}$, much of which is not available to support algal growth. There is need to shift nutrient control BMP development/evaluation on those forms of $\mathrm{N}$ and $\mathrm{P}$ that support algal growth.

\section{IMPORTANCE OF LIGHT PENETRATION}

Almost all algal growth in waterbodies is light-limited. This results in the algae being able to photosynthesize in fertile waterbodies only in the upper few feet, due to the self-shading effects of planktonic algae. It is important to understand the coupling between nutrient loads to 
waterbodies and their eutrophication-related water quality as influenced by inorganic turbidity and natural color. It is well-established that erosion from a waterbody's watershed increases the turbidity in waterbodies, which in turn decreases light penetration and thereby slows algal growth. There are situations, however, where the control of erosion in a waterbody's watershed can result in greater algal growth for the same nutrient concentration than would occur if the waters were still turbid from erosion in the watershed.

\section{NUTRIENT EXPORT COEFFICIENTS}

Nutrient export coefficients are the amounts of nitrogen or phosphorus exported from an area over a specific time period. They are typically expressed as grams P per square meter per year, or pounds N per acre per month, or some other mass-area-time units. Rast and Lee (1983), based on the US OECD Eutrophication studies, developed nutrient export coefficients based on about 100 waterbodies' watersheds located across the US. These are shown in Table I.

Table I. Watershed Nutrient Export Coefficients

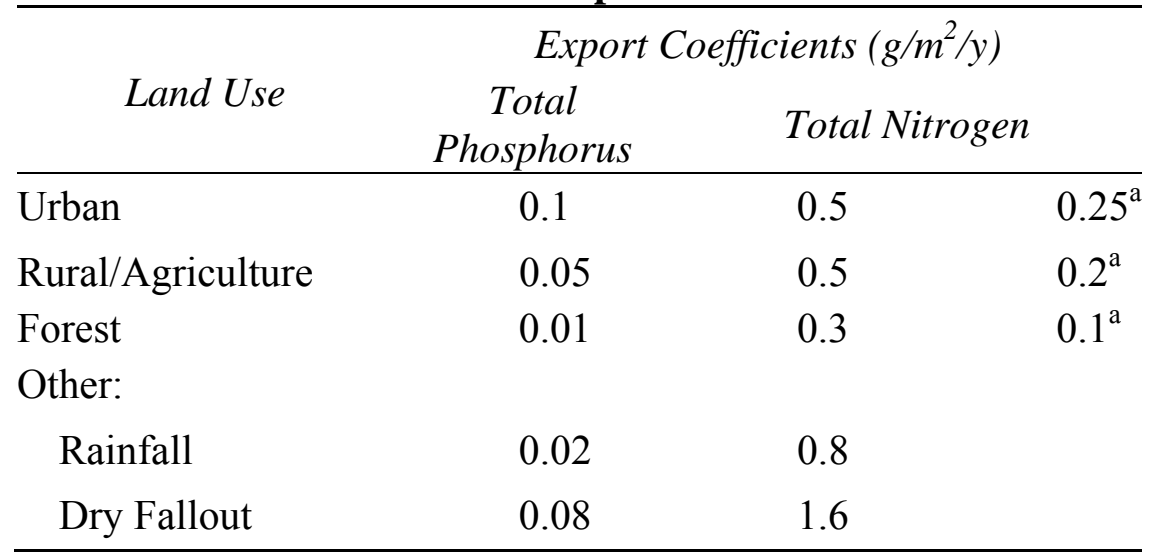

${ }^{\text {a }}$ Export Coefficients Used in Calculating Nitrogen Loadings for Waterbodies in Western US. From Rast and Lee (1983).

While the actual export coefficient depends on the particular setting, these values have been shown in many situations to provide sufficient reliability to estimate the potential significance of various types of land use in a waterbody's watershed as a source of nitrogen and phosphorus. Nutrient export coefficients for agricultural lands should be evaluated based on soil characteristics, types of crops grown, and other factors that tend to influence the amount of nitrogen and phosphorus exported from the land.

There will be situations where the annual export coefficient is not appropriate, such as for waterbodies with short (a few weeks to a few months) hydraulic residence times. Under these conditions, monthly export coefficients should be used, where attention is given to the sources of those nutrients that are responsible for excessive algal growth that impairs the waterbody's water quality.

\section{NUTRIENT CRITERIA}


Beginning in the 1960s, there was considerable interest in several parts of the US, especially the Midwest/Great Lakes region, in developing nutrient control programs to control excessive fertilization of waterbodies. It was recognized then that the cultural activities of man, through developing cities and agricultural activities, increased the nutrient export from land, which could increase the fertility of the waterbodies receiving the runoff/discharges. At that time, the primary focus of nutrient control was devoted to treating domestic wastewaters for phosphorus control. During the 1960s and 1970s, there was considerable research done on the relationships between nutrient loads to waterbodies and their impact on eutrophication-related water quality. By the late 1970s, the US EPA essentially terminated all efforts devoted to eutrophication management and shifted their emphasis to the control of "rodent" carcinogens that are regulated as Priority Pollutants. This shift in emphasis was not based on finding that eutrophication of waterbodies was any less of a cause of impairment of beneficial uses, but was based on political considerations. In the late 1990s, the US EPA began again to give consideration to excessive fertilization of waterbodies as a major cause of impairment of the nation's waters. At that time the Agency decided to attempt to develop numeric, chemical-specific water quality criteria for nitrogen and phosphorus, which would become the primary basis by which the Agency regulates excessive fertilization of waterbodies.

In formulating the Agency's approach for developing nutrient criteria, the Agency staff and its advisors largely ignored the large amount of work that was done in the 1960s and 1970s relating nutrient loads to waterbodies to the eutrophication-related water quality. At that time, it was well-established that each waterbody behaves differently with respect to how it utilizes nutrients to produce aquatic plants, which in turn impair the beneficial uses of the waterbody. The Agency's approach for developing chemical-specific nutrient criteria focused on developing background concentrations of nutrients in various types of waterbodies that would be present in the absence of the activities of man in the watershed. While that approach, like the chemical concentration-based approach that the US EPA has been using since the late 1980s to regulate potentially toxic constituents such as heavy metals, is easy to administer, it, like the situation with regulation of heavy metals, is not technically valid, and can be wasteful of public and private funds in controlling nutrients from agricultural and urban areas.

The Agency's approach of attainment of worst-case-based water quality criteria/standards for regulating heavy metals and other potentially toxic constituents has been implemented for domestic and industrial wastewaters. Those discharging to domestic wastewater collection systems are a "captive audience," where unnecessary expenditures for treatment works associated with over-regulating the discharge of constituents is passed on to the rate-payers. However, the chemical-specific chemical concentration approach is not an implementable approach with respect to regulating stormwater runoff-associated constituents which avoids unnecessary expenditures for constituent control and will not be implemented to control heavy metals or nutrients in urban area and highway stormwater runoff and other point and non-point sources. The high cost of managing stormwater runoff-associated constituents, including nutrients, to meet nutrient criteria/standards based on pre-cultural nutrient concentrations in waterbodies will cause the public, who must ultimately pay for the chemical constituent management, to critically review the appropriateness of a particular nutrient control program in protecting the beneficial uses of the waterbodies of interest to them. 
One of the problems with nutrient control, especially associated with the US EPA's approach of one numeric value fits all waterbodies of a certain type in an ecoregion, is that, in the moderate nutrient enrichment situation, which can be well above natural background nutrient levels, nutrients are of value in improving beneficial uses of waterbodies. To attempt to return waterbodies to the pre-cultural nutrient status would, to some, be disastrous to the fisheries of the waterbodies. As described by Lee and Jones (1991) in their paper, "Effects of Eutrophication on Fisheries," there is a well-established link between available nutrient concentrations and fish biomass (Figure 3). The classic example of this issue is Lake Erie, where, during the 1960s, the popular press portrayed Lake Erie as "dying." The problem was that there was DO depletion in the deeper waters of the lake. The lake, however, was not dying. It was actually "too alive," because of the large numbers of algae present. This situation prompted the US and Canadian regulatory authorities to cause domestic wastewater treatment plants effluents to be treated for phosphorus removal. Also, agriculture in the region began to shift to no-till farming in an effort to reduce the phosphorus input associated with erosion. The fisheries in Lake Erie at the time that it was "dying" were excellent. The fishermen in Lake Erie are now complaining about the poor-quality fisheries due to the overall reduced productivity of the lake. This situation could readily occur if the US EPA adopts nutrient criteria which represent "pristine" conditions.

Agriculture and other nutrient dischargers face the use of nutrient ( $\mathrm{N}$ and $\mathrm{P}$ ) criteria to regulate nutrient releases from land. The US EPA's (1998, 1999, 2000b) current approach for developing nutrient criteria will likely lead to many waterbodies becoming listed as Clean Water Act 303(d) "impaired" waterbodies due to nutrient concentrations above the criterion values. The 303(d) listing will lead to the need to develop TMDLs to control nutrient runoff from agricultural and urban lands and other sources. Because of this situation, agricultural/urban stormwater runoff management interests should become involved in the US EPA's Regional Technical Assistance Group (RTAG) efforts to establish nutrient criteria in their area, to ensure that appropriate criteria are developed for the receiving waters of runoff from agricultural/urban lands and other nutrient sources.

The US EPA has proposed two approaches for developing nutrient criteria. The national chemical concentration-based default values are based on nutrient concentrations in the water, which are estimated based on pre-cultural activities (no agricultural or urban activities) in the waterbody's watershed. This relationship is shown in Figures 5 and 6.

As shown in Figure 5, the US EPA default nutrient criteria are based on the nutrient concentration at the intersection of the "reference" stream 75 th percentile nutrient concentration with the 25 th percentile concentration for all streams as the criterion value. If there are no reference streams in an area then the 25 th percentile of the nutrient data for a stream becomes the nutrient criterion. This approach is arbitrary and has nothing to do with regulating the impact of the nutrients on the beneficial uses of the waterbody. Ditoro and Thuman (2001) have commented that the US EPA's default nutrient criteria approach has neglected the link between nutrient concentrations and water quality impacts and implies that 75 percent of the waterbodies in an ecoregion will not meet the nutrient criteria. 
Figure 5-US EPA Default Nutrient Criteria Development Approach

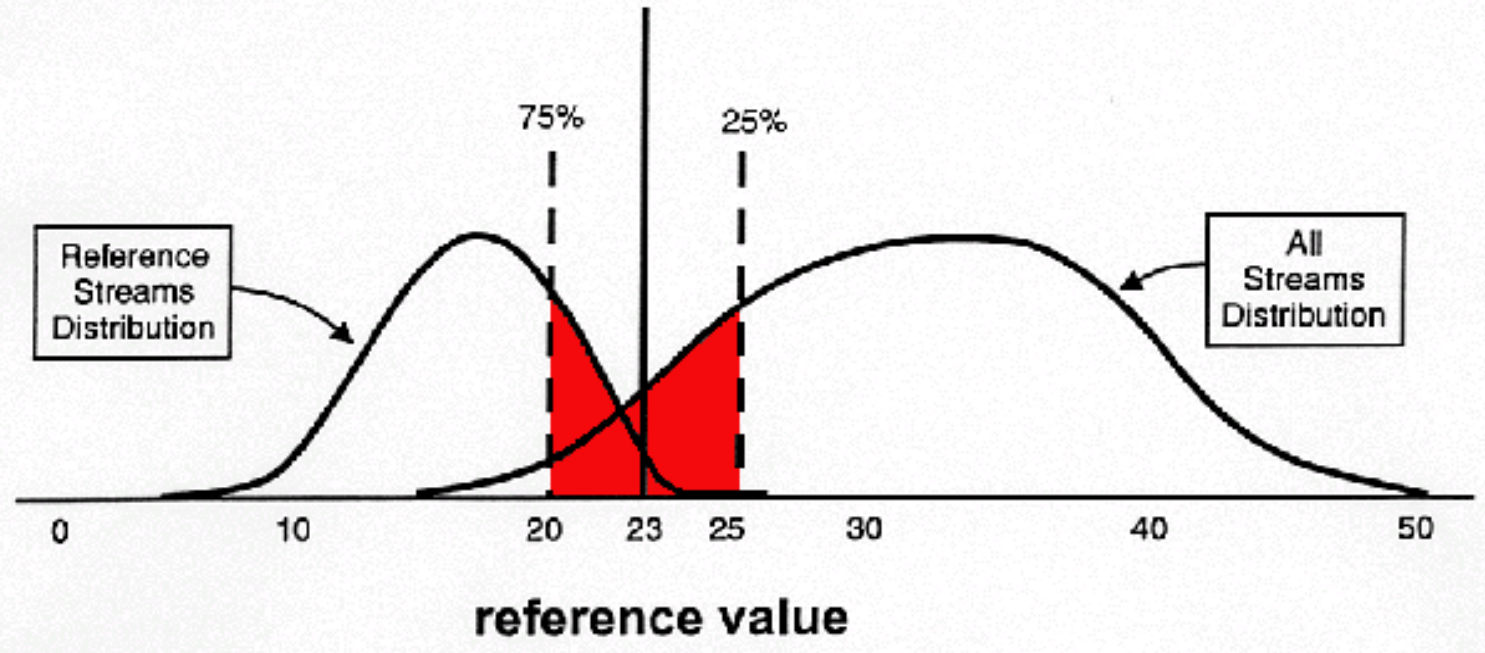

Figure 8. Selecting reference values for total phosphorus concentration $(\mu \mathrm{g} / \mathrm{L})$ using percentiles from reference streams and total stream populations.

Source: US EPA, Nutrient Criteria Technical Guidance Manual, Rivers and Streams (2000c).

The US EPA default nutrient criteria development approach is made even more unreliable as the result of the Agency using total P and TKN as the "nutrients" that are used in selecting the default criterion value. For many waterbodies, especially in streams and rivers during elevated flows, large amounts of the total $\mathrm{P}$ and TKN are not in and do not convert to algal available forms. The US EPA's approach for developing ecoregion-based default nutrient criteria is obviously technically flawed and can readily lead to inappropriate regulation of nitrogen and phosphorus. Additional information on developing the default nutrient criteria is provided in US EPA (2000c).

The Agency states that if states do not develop "scientifically defensible" nutrient criteria by the 2004 deadline, the default nutrient criteria will be imposed on the states as the state nutrient water quality standard. While recent information from the Bush administration (Grubbs, 2001) indicates that the 2004 deadline may be slipping, the Agency staff is still claiming that the states must have well-developed nutrient criteria by that date. 
Figure 6-Nutrient Criteria Issues

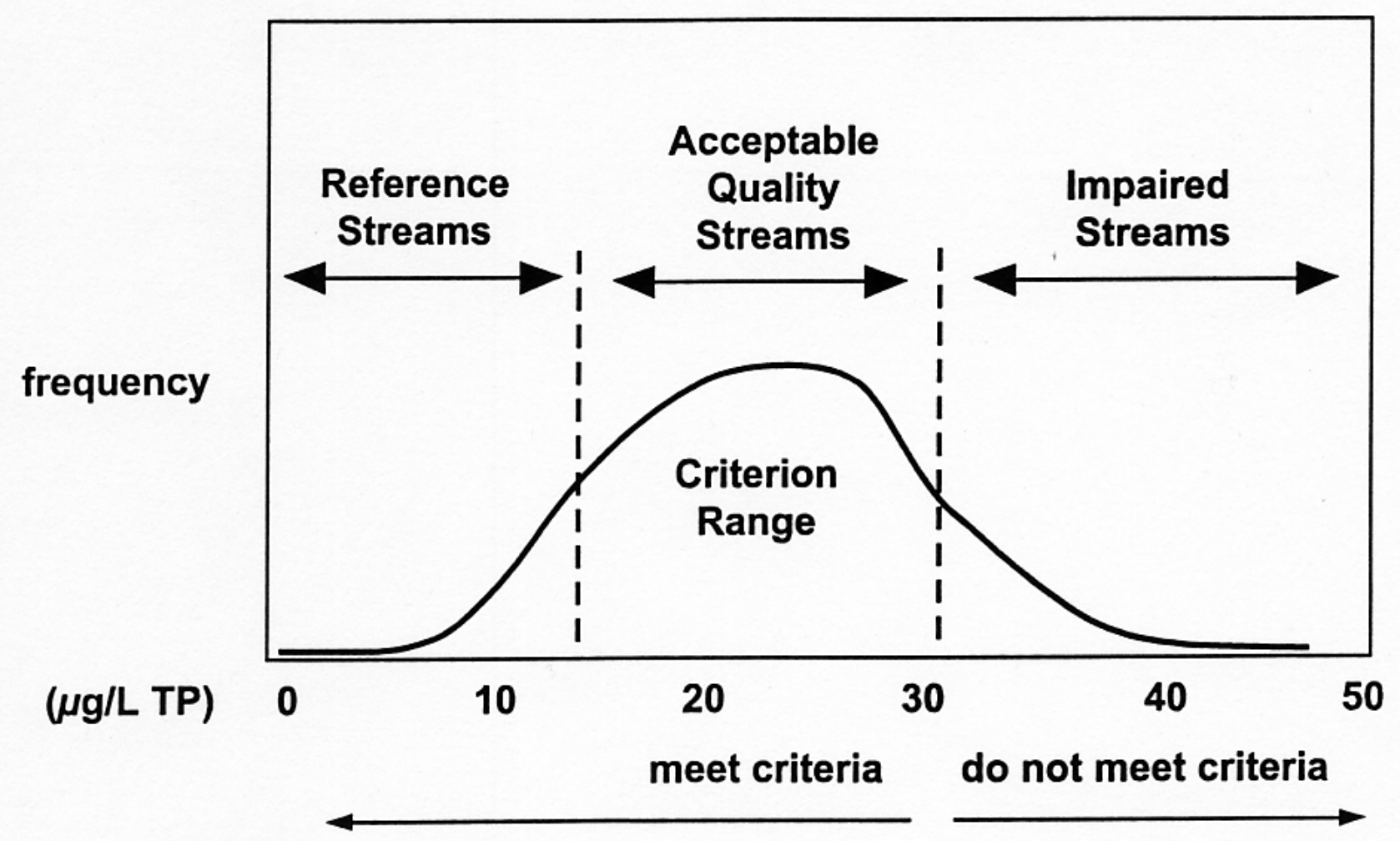

Figure 9. Frequency distribution divided into three segments that represent (from left to right) high-quality reference streams, acceptable quality streams, and impaired streams.

Source: US EPA, Nutrient Criteria Technical Guidance Manual, Rivers and Streams (2000c).

The US EPA default nutrient criteria development is more of the inappropriate approach that the US EPA has been using since the early 1980s in which the Agency is trying to reduce impacts of chemicals on water quality/beneficial uses to a single numeric value. Lee and Jones-Lee (1996) discussed the urgent need for the US EPA to stop the chemical concentration-based approach for regulating water quality and instead focus on regulating chemical impacts. Adoption of the chemical impact on water quality/impairment of beneficial uses approach will lead to a much more technically valid, cost-effective management of real, significant water quality impairments. Basically, the Agency is attempting to develop chemical concentration-based numeric nutrient criteria which are similar to the water quality criteria for controlling toxics. With respect to toxics, it is appropriate to consider controlling the toxicity of constituents to protect aquatic life 
from toxicity. However, applying this same approach to nutrients could lead to erroneous assessments of desirable nutrient loads/concentrations for waterbodies.

In developing the appropriate nutrient criteria, it is suggested that the TMDL development approach is an appropriate approach to follow. This approach involves the following steps:

- Developing a problem statement of the excessive fertilization situation of concern.

- Establishing the goal of nutrient control (i.e., the desired eutrophication-related water quality).

- Determining nutrient sources, focusing on available forms.

- Establishing linkage between nutrient loads and eutrophication response (modeling).

- Initiating a Phase I nutrient control implementation plan to control the nutrients to the level needed to achieve the desired water quality.

- Monitoring the waterbody for three to five years after nutrient control is implemented to determine whether the desired water quality is being achieved.

- If not, initiating a Phase II where, through the monitoring results, the load-response model is improved and thereby able to more reliably predict the nutrient loads that are appropriate for the desired water quality.

This approach is an iterative approach, where, over a period of at least five to possibly 15 years, through two or more consecutive phases, it will be possible to achieve the desired water quality and thereby establish the nutrient loads which can be translated to in-waterbody concentrations and, therefore, the nutrient criteria for the waterbody. Information on several of these components is discussed below.

\section{ISSUES THAT NEED TO BE CONSIDERED IN DEVELOPING APPROPRIATE NUTRIENT CONTROL PROGRAMS}

There are a number of key issues that need to be considered/evaluated in formulating nutrient control programs, the most important of which is the nutrient load-eutrophication response relationship for the waterbody(ies) of concern. Each waterbody has its own water quality-related load-response relationship that needs to be evaluated. As discussed herein, the notion that this evaluation should be restricted to just the US EPA's "ecoregion" approach, where waterbodies of a particular type, such as a lake, river, stream, etc., in an ecoregion can all have the same nutrient criteria, is fundamentally flawed since it ignores the vast amount of work that was done in the 1960s and 1970s in developing technically valid nutrient control programs for various types of waterbodies located in various areas.

The primary issue of concern is the identification of the nutrient loads to a particular waterbody that cause or contribute to excessive fertilization of the waterbody -- i.e., cause water quality use impairment. Associated with this are the issues of when the water quality problems occur (in the summer, fall, winter, etc.), how they are manifested (planktonic algae, attached algae, macrophytes), what the desired eutrophication-related water quality is for the waterbody, what the hydraulic residence time (filling time) of the waterbody is and when the nutrients enter the waterbody that cause the water quality problems. The relationship among these various factors has recently been reviewed by Jones-Lee and Lee (2001). The ultimate goal of managing eutrophication-related water quality is to assess how the magnitude of the nutrient-caused water 
quality problem changes with a change in nutrient loads. This requires that an assessment of the cost of nutrient control to achieve desired water quality be developed.

The US EPA's nutrient chemical concentration-based default criteria development approach does not adequately consider the variety of factors that influence how nutrients impact water quality beneficial uses of waterbodies. Not all nutrients above pre-cultural conditions are adverse to water quality. For many waterbodies, nutrients above "background" are beneficial to aquatic life resources. The development of appropriate nutrient criteria requires a balancing of the desired water quality in waterbodies with the cost of controlling nutrients from various sources.

The site-specific nutrient criteria development approach advocated herein is potentially supportable by the US EPA. The Agency staff has, on a number of occasions, indicated that a site-specific approach to development of nutrient criteria for a waterbody or group of waterbodies could be accepted by the Agency, provided that it is based on a "scientifically defensible" approach. Thus far, the Agency has not defined what it means by "scientifically defensible," especially as it relates to situations where a waterbody would have high nutrient concentrations from agricultural runoff, where the nutrients are stimulating algal growth as measured by planktonic algal chlorophyll, well above those that, in many waterbodies, would cause significant water quality deterioration; however, in the waterbody of concern which has the elevated nutrients and chlorophyll, there is no impairment of the beneficial uses. This is a result of the fact that turbidity, derived from erosion in the watershed, masks the excessive growths of algae. This turbidity causes the water to be "brown," with the result that the chlorophyll "greenness" is not manifested. This situation is not atypical of the situation that occurs in many of the major rivers in the US.

An example of this type of situation occurs in the San Joaquin River above the Deep Water Ship Channel near Stockton, California. The public, regulatory agencies, and others do not perceive the San Joaquin River in that region as an impaired waterbody due to excessive nutrients and the associated algal growth, even though the algal concentrations are well-above those that, in some waterbodies, would cause water quality deterioration. It remains to be seen whether the US EPA would allow nitrogen and phosphorus concentrations a factor of 10 or more times the pre-cultural nutrient levels, where planktonic algal chlorophyll has developed to high levels but is not manifested as an impairment of the beneficial uses of the San Joaquin River.

There are, however, impairments of the downstream San Joaquin River Deep Water Ship Channel, due to the elevated nutrients which develop into algae, which, upon reaching the Channel, die and become oxygen demand. Under these conditions, the nutrient criteria development should focus on controlling nutrient discharges in the watershed which could, in turn, limit the algal biomass that enters the Deep Water Ship Channel which leads to DO depletions below the water quality objective. Since, as discussed by Lee and Jones-Lee (2000, 2002), the DO depletion problem is a summer-fall problem, there would be no need to limit the high nutrient concentrations/loads associated with winter-spring flows in the San Joaquin River, since there is normally no DO depletion problem in the Deep Water Ship Channel at those times. However, since part of the high winter-spring flows in the San Joaquin River are exported from the Delta by water utilities and stored in water supply reservoirs where excessive algae develop which cause tastes and odors for the water utilities, the nutrient management program could be 
based on limiting the input of nutrients to the San Joaquin River that lead to excessive algal growths in water supply reservoirs which are principally located in Southern California, hundreds of miles from where the nutrients originated in the San Joaquin River watershed. Attempts to limit nutrient input to the Sacramento San Joaquin River Delta because of the potential impacts of the nutrients on water supply water quality associated with the export and storage of Delta water in water utility reservoirs could be met with significant opposition by fisheries resource managers, who would see reducing nutrient input to the Delta as being contrary to improved fish production. There will be situations where the development of nutrient criteria, such as in the San Joaquin River watershed and Delta, cannot be meaningfully approached through the US EPA's ecoregion default criteria development approach. It will require a highly sophisticated, carefully-developed evaluation and management of nutrient sources and their impacts to protect the beneficial uses of these waterbodies without unnecessary nutrient control programs.

\section{Evaluating Allowable Nutrient Loads to Waterbodies}

To establish the allowable nutrient loads for a waterbody, it is necessary to model the nutrient load-eutrophication response relationships for the waterbody. There are basically two types of models:

- An empirical, statistical model, such as the Vollenweider-OECD Eutrophication model discussed herein, which involves a large database on how nutrient concentrations or loads relate to the nutrient-related water quality characteristics of the waterbody.

- A deterministic model, in which differential equations are used to describe the primary rate processes that relate nutrient concentrations/loads to algal biomass.

The deterministic modeling approach, while able to be tuned to relate nutrient loads to eutrophication response, may have limited predictive capability. Because of the number of equations used, there is no unique solution to the model, and therefore, tuning the model may not properly represent the conditions that would be important in predicting eutrophication response (such as planktonic algae) under altered nutrient loads.

\section{Desired Nutrient-Related Water Quality}

The first step in developing appropriate nutrient water quality criteria is to establish the desired nutrient-related water quality for the waterbody(ies). This should be done through a public process conducted by the regulatory agency. Such issues as no violation of the average/worstcase diel $\mathrm{DO}$ and $\mathrm{pH}$, minimizing adverse impacts of nutrients on algal-caused domestic water supply raw water quality (i.e., controlling tastes and odors, filter runs, etc.) and water clarity/Secchi depth are important eutrophication-related water quality parameters for those waterbodies where the excessive fertilization is manifested as planktonic algae. One of the frequently used indicators of eutrophication-related water quality is water clarity. Water clarity is often measured by a Secchi depth. The Secchi depth is based on the visual observation of the depth at which a $20 \mathrm{~cm}$ circular disk painted with black and white quadrants can be observed from the surface. With respect to water clarity, the issue is basically one of the depth of the waterbody at which the bottom sediments can still be seen from the surface. Waterbodies with high degrees of clarity (i.e., the bottom can be seen even at depths of 20 or more feet) are ones 
with low planktonic algal content. For more eutrophic waterbodies, typically the sediments can only be seen at a depth of a few feet.

Another factor that is important is water greenness, which is measured by planktonic algal chlorophyll. In areas where there are a number of lakes and reservoirs with different areal nutrient loads and, therefore, degrees of fertility, the public has the opportunity to compare waterbodies that are green with those that are clear. The public's perception of high water quality in those areas where there are marked differences in lake water clarity is quite different than in areas where all the waters have the same general greenness due to planktonic algae. A factor that influences the perception of greenness of a waterbody is the inorganic turbidity. Often, quite high levels of planktonic algal chlorophyll can be present in a shallow waterbody or river without the public perceiving it to be excessively fertile, if the waterbody is brown due to inorganic turbidity.

Figure 7 is a modification of Vollenweider's (1976) relationship in which he defined "excessive" and "permissible" phosphorus loadings to lakes and reservoirs, considering the waterbody's mean depth and hydraulic residence time. Rast and Lee (1978), based on the results of the US OECD Eutrophication studies, expanded this relationship to include mean summer planktonic algal chlorophyll and Secchi depth that is due to planktonic algae.

From this relationship, the stakeholders in a waterbody's watershed can determine the desired greenness of the water and water clarity. Other response parameters (such as domestic water supply tastes and odors, etc.) can be included in this relationship. Once these are defined, then the allowable available phosphorus and/or nitrogen load can be determined. This is an appropriate approach to follow in establishing critical nutrient concentrations/loads for waterbodies that are found to follow the results of the Vollenweider-OECD Eutrophication study program discussed herein.

As discussed by Lee, et al. (1995a,b,c), if the water quality problems due to excessive fertility are due to macrophytes, attached algae, etc., an assessment of the percent of the area with excessive concentrations of water weeds should be made, in terms of both the current conditions and the conditions that are desirable. Shallow water area water weeds are important fish habitat.

For lakes/impoundments that do not follow the phosphorus load-eutrophication response relationship that was developed in the OECD Eutrophication studies, as well as rivers and streams, it is necessary to conduct site-specific studies to determine the eutrophication-related water quality of interest to the public/stakeholders impacted by fertilization of the waterbody. As part of reviewing the desired water quality, an assessment should be made of the desired fisheries. For waterbodies that stratify, an assessment should be made as to whether there is a desire to maintain coldwater fisheries in the hypolimnion. Also, consideration should be given to developing a waterbody that has a high-value sports fishery, compared to one with low nutrients which would have low planktonic algae, high water clarity, but low fish production.

Carlson (1977) proposed a trophic state index system which is based on total phosphorus, chlorophyll, and Secchi depth. Except for the inclusion of total phosphorus as a parameter, this 
approach was an improvement over previously-discussed multiparameter approaches that have been used in the past. He developed a spectrum of Secchi depths and chlorophyll and $\mathrm{P}$ concentrations for a group of Minnesota lakes and then outlined a numerical ranking system for waterbodies based on their relative positions within these spectra. There are, however, several

Figure 7-Modified Vollenweider Phosphorus Loading Relationship

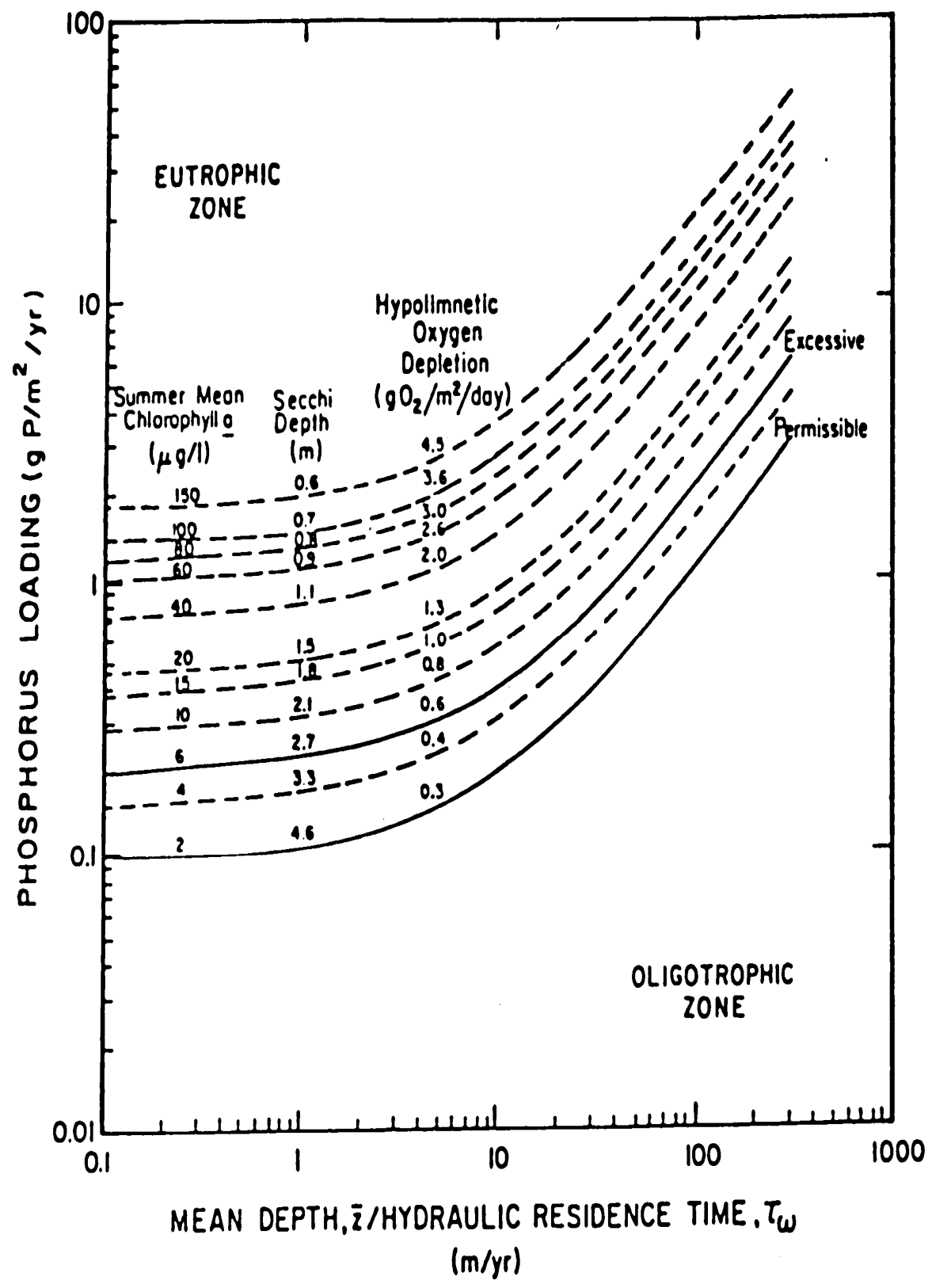

Relationship Between Vollenweider Phosphorus Loading Diagram, Summer Mean Chlorophyll a and Secchi Depth (After Rast and Lee, 1978) 
technical problems with Carlson's trophic state system. As discussed by Rast and Lee (1978), Carlson's index is based on a limited number of waterbodies in one geographical region of the US. It also fails to consider the beneficial uses of the waterbody being considered, how the values of the evaluation parameters affect the beneficial uses, and the public's perception of water quality.

The summing of values assigned for the various response parameters has inherent in it the same problems of skewing for the multiparameter indices. In addition, while Secchi depth can be a useful eutrophication response parameter, it must be used judiciously. There are situations in which inorganic turbidity - erosional material or color exert a significant control over water clarity, masking the contribution made by planktonic algae. Under these conditions it would certainly be improper to include in a trophic state indexing system, a factor for water clarity. The problems associated with using in-lake $\mathrm{P}$ concentrations as an indicator of water quality have been discussed previously herein and by Rast and Lee (1978).

A second component of the recommended approach for developing nutrient criteria is to evaluate the nutrient loads/concentrations to achieve the desired nutrient-related water quality. If the waterbody is a lake or reservoir and the water quality problem is excessive planktonic algae, it should be determined whether the waterbody fits the updated Vollenweider-OECD Eutrophication modeling results (see Jones and Lee, 1982, 1986). If so, then it is possible to predict the desired water quality, based on the relationships developed by Vollenweider (1976), which were formulated based on the OECD (1982) and post-OECD Eutrophication studies. Figure 8 presents the results of the OECD and post-OECD Eutrophication studies that show the relationship between the normalized phosphorus load to the waterbody and the planktonic algal chlorophyll, Secchi depth, and hypolimnetic oxygen depletion rate that results in the waterbody. These relationships were developed by Rast and Lee (1978).

Figure 9 presents the updated normalized phosphorus load-planktonic algal chlorophyll relationship that was developed by Jones and Lee (1986). Each of the dots on this figure, as well as Figure 8, represents a lake, reservoir or estuary where the nutrient load-eutrophication response has been measured for at least a year. At this time, there are over 750 waterbodies that make up this database.

Lee and Jones (1992) have provided information on the minimum monitoring program needed for most waterbodies to evaluate whether the phosphorus load-eutrophication response relationship for the waterbody fits the results obtained in the Vollenweider-OECD Eutrophication studies and post-OECD studies summarized by Jones and Lee (1986). In general, this monitoring program involves sampling the tributaries to the waterbody at about biweekly intervals over one year for measurements of flow and nitrogen and phosphorus compounds. Also, at about weekly intervals, for each of the major parts of the waterbody, samples are taken of the water column for planktonic algal chlorophyll, Secchi depth, temperature, and dissolved oxygen. 
Figure 8-US OECD Eutrophication Study Results

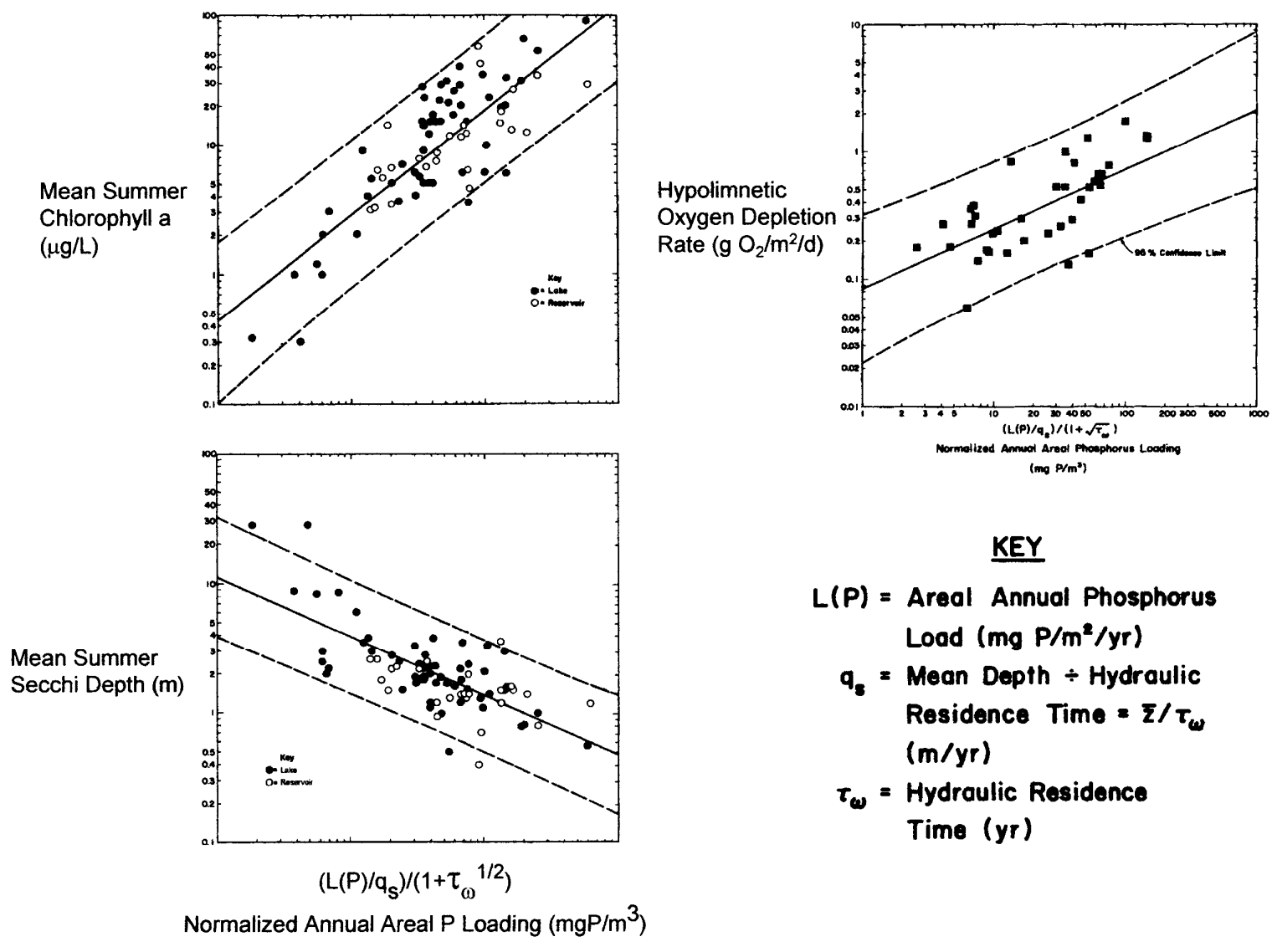

From Rast and Lee (1978).

One of the issues of concern in excessive fertilization management is whether small amounts of phosphorus or other nutrient control will have a significant impact on the waterbody's eutrophication-related water quality. In the late 1960s through mid-1970s, there was considerable discussion about the potential value of banning detergents containing phosphate. Many of the detergent phosphate ban proponents claimed that even though the phosphorus contributed to domestic wastewaters from detergents was a small part of the total phosphorus present in domestic wastewaters, removal of detergent phosphate would result in a significant improvement in the waterbody's eutrophication-related water quality. Lee and Jones (1986) examined this situation and concluded that at least 20 to 25 percent of the available phosphorus load to waterbodies needs to be controlled to effect a discernible change in the eutrophicationrelated water quality, such as planktonic algal chlorophyll or algal-controlled Secchi depth. This 
relationship is shown in Figure 10. This relationship is not restricted to detergent phosphate or wastewater-derived phosphate, but is applicable to all sources of available phosphorus.

Figure 9-Updated Normalized Phosphorus Load-Planktonic Algal Chlorophyll Results.

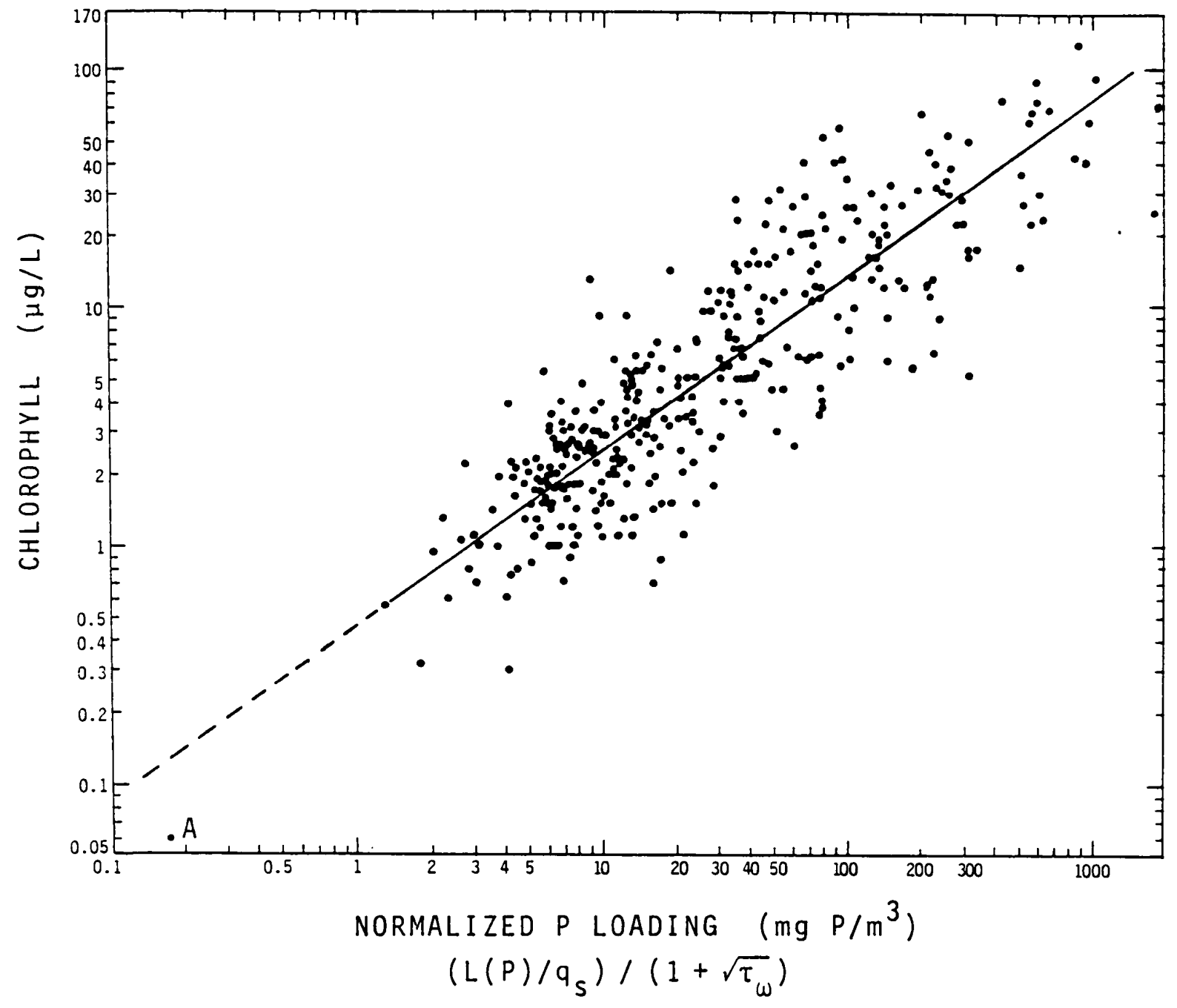

From Jones and Lee (1986).

\section{IMPACT OF PHOSPHORUS CONTROL UNDER SURPLUS PHOSPHORUS CONDITIONS}

A number of studies have shown that significant decreases in algal related water quality problems occur in waterbodies in which phosphorus control on the inputs to the waterbodies is practiced. Rast, et al. (1983) examined the literature for information on how planktonic algal chlorophyll changed in waterbodies where phosphorus control was practiced in the watershed. This information is presented in Figure 11. The basic relationship presented in Figure 11 is the Vollenweider normalized loading of phosphorus relative to the planktonic algal chlorophyll that 
develops in the waterbody. It would be expected that waterbodies that respond to phosphorus loading changes would track a reduction in phosphorus load parallel to the line of best fit for the normalized phosphorus load-planktonic algal chlorophyll relationship. As shown, this is what occurs for many waterbodies.

Figure 10-Impact of Altering Phosphorus Load on Eutrophication Response.

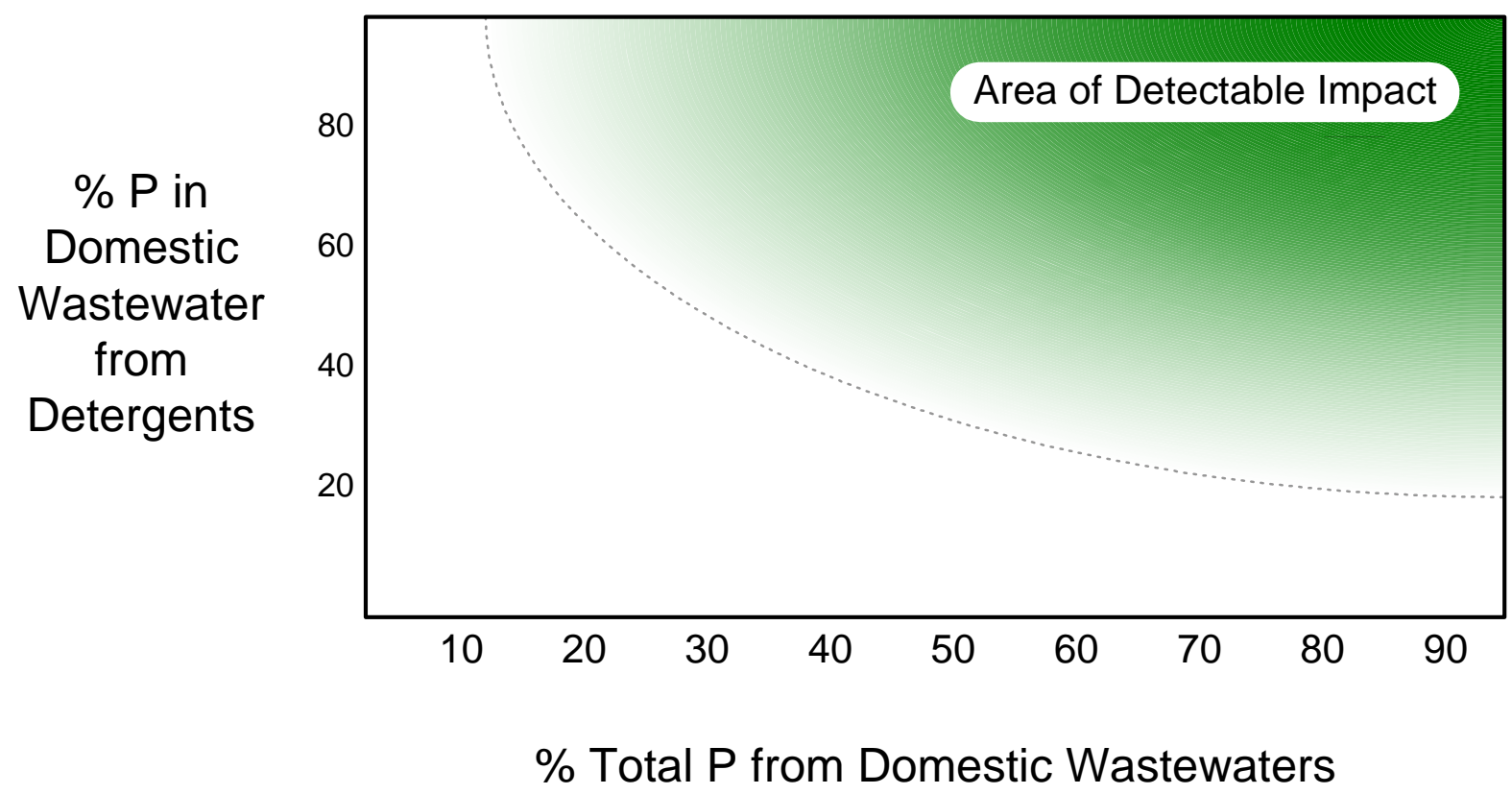

From Lee and Jones (1986).

It is important to note, however, that the phosphorus concentrations in these waterbodies were not at growth-rate-limiting concentrations. Lee (2001) has recently discussed this issue, pointing out that improvements in eutrophication-related water quality can occur even though growthrate-limiting concentrations of phosphorus were not achieved in the phosphorus control program. Figure 12 shows the impact of reducing phosphorus loads to the Rhine River in Europe on the planktonic algal chlorophyll found in the River. A similar situation was observed when the phosphorus loads to the Ruhr River in Europe were reduced (Albrechtl, 1988). The DO depletion problems that had been experienced in the Ruhr River were significantly decreased following reduced phosphorus loading. Decreases in phosphorus loading/in-river concentrations to these rivers resulted in decreases in planktonic algae, which reduced the oxygen demand.

\section{RATE OF RECOVERY}

One of the issues of particular concern in eutrophication management is the rate of recovery of a waterbody following reduction in the nutrient/phosphorus loads. The large amounts of phosphorus stored in lake sediments have caused some to incorrectly conclude that reducing the phosphorus load from the watershed would result in little improvement in water quality. This would be especially true for waterbodies which have long hydraulic residence times. However, Sonzogni, et al. (1976) have demonstrated that the rate of recovery of eutrophication-related water quality for waterbodies where a reduced phosphorus load has occurred is governed by the 
phosphorus residence time in the waterbody. The phosphorus residence time is the total mass of phosphorus in the waterbody divided by its annual load. It accounts for phosphorus removal to the sediments and through the waterbody's outlets. This is typically much shorter than the hydraulic residence time.

\section{Figure 11-Effect of Phosphorus Loads to Waterbodies on Planktonic Chlorophyll}

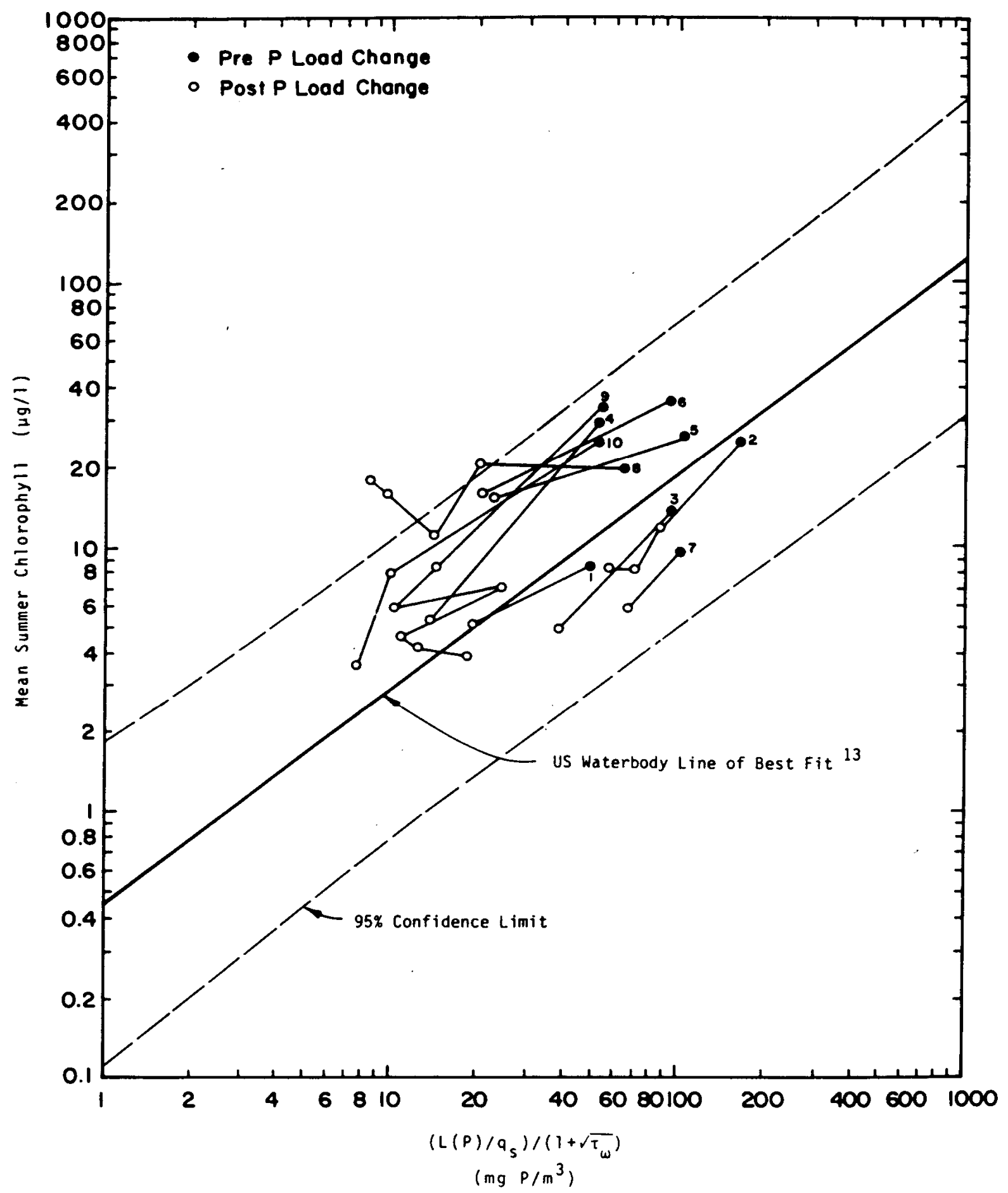


Figure 12-Impact of Altering P Concentration on Rhine River Chlorophyll

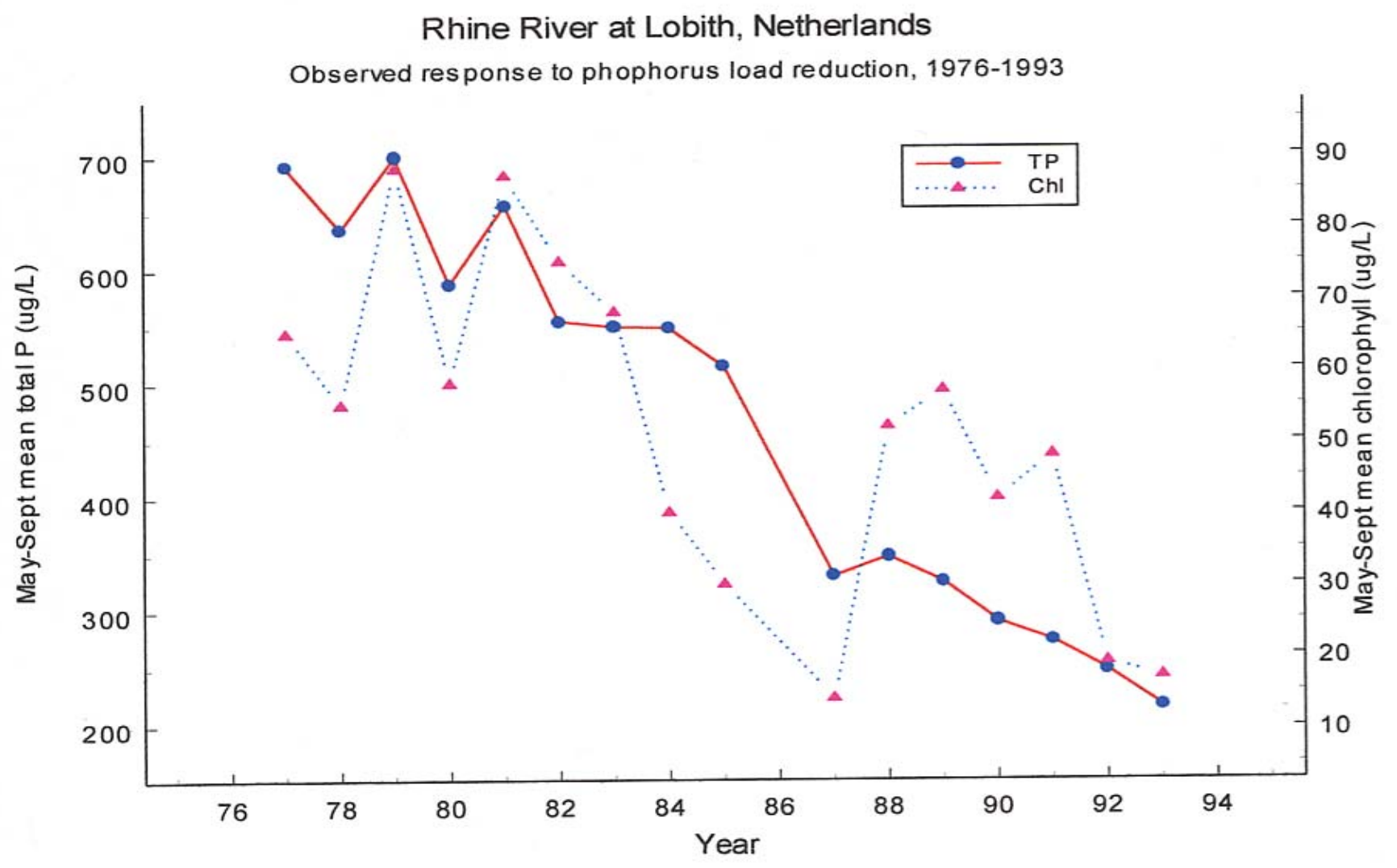

Source: Dutch Governmental Institute on Inland Water Management and Waste Water Treatment (1994). Provided by E. Van Nieuwenhuyse, USBR, Sacramento, CA..

\section{CONCLUSIONS AND RECOMMENDATIONS}

Excessive fertilization of waterbodies is a major cause of water quality impairment.

Agricultural, and in some situations, urban runoff/discharges are significant sources of nutrients which contribute to excessive fertilization of some waterbodies. There are a wide variety of factors that influence how nutrients derived from particular types of sources, such as agricultural land runoff, impact the fertility of waterbodies receiving this runoff. An area of particular concern to agricultural/urban interests is the availability of phosphorus in agricultural land runoff to support algal growth in the waters receiving this runoff. 
US EPA ecoregion-based nutrient criteria are not based on a technically valid approach for developing appropriate nutrient concentrations to protect the beneficial uses of waterbodies without unnecessary expenditures for chemical constituent control. Those concerned about the management of excessive fertilization in a particular waterbody should work with the waterbody's stakeholders to develop site-specific nutrient control objectives and appropriate control programs to meet these objectives. This is a far more technically valid approach than the US EPA's ecoregion-based default nutrient criteria development approach. There is need for site-specific investigations to determine the amount that agricultural/urban nutrient discharges/ releases contribute to the excessive fertilization of some waterbodies. Managing excessive fertilization of waterbodies using technically valid, cost-effective approaches requires understanding of nutrient load-eutrophication response relationships for the waterbody.

\section{REFERENCES}

Albrechtl, Detlef R. (1988) "Results of Fifteen Years of Continuous Monitoring of Water Quality in the Ruhr River Heavily Affected by Residual Point and Nonpoint Pollution," American Water Resources Association's Nonpoint Pollution: - Policy, Economy, Management, and Appropriate Technology, pp. 271-280.

Carlson, R. E. (1977) Trophic State Index for Lakes., Limnol. and Oceanogr., 22:361-369.

Ditoro, D. M. and Thuman, A. J. (2001) "It Takes Skill to Make Music," Stormwater 2:8 July/August.

Grubbs, G. (2001) "Development and Adoption of Nutrient Criteria into Water Quality Standards," Office of Science and Technology, US Environmental Protection Agency, WQSP0101, Washington, D.C., November 14.

Jones, R. A. and Lee, G. F. (1982) "Recent Advances in Assessing the Impact of Phosphorus Loads on Eutrophication-Related Water Quality," Journ. Water Research, 16:503-515.

Jones, R. A. and Lee, G. F. (1986) "Eutrophication Modeling for Water Quality Management: An Update of the Vollenweider-OECD Model," World Health Organization's Water Quality Bulletin 11(2):67-74, 118.

Jones-Lee, A. and Lee, G. F. (2001) "Evaluation of Inorganic and Organic Nutrient Source Impacts in Nutrient TMDLs," Proceedings of the AWWA/WEF/CWEA Joint Residuals and Biosolids Management Conference, San Diego, CA, Available on CD-ROM and from www.gfredlee.com.

Lee, G. F. (1971) "Eutrophication," Encyclopedia of Chem. Tech.- Supplement, John Wiley \& Sons, pp 315-338.

Lee, G. F. (2001) "Potential Impact of Phosphorus Control on Low DO in the SJR DWSC," report to the SJR DO TMDL Steering Committee Technical Advisory Committee, G. Fred Lee \& Associates, El Macero, CA, May. 
Lee, G. F. and Jones, R. A. (1986) "Detergent Phosphate Bans and Eutrophication," Environ. Sci. \& Technol., 20(4):330-331.

Lee, G. F. and Jones, R. A. (1991) "Effects of Eutrophication on Fisheries," Reviews in Aquatic Sciences, 5:287-305, CRC Press, Boca Raton, FL.

Lee, G. F. and Jones, R. A.(1992) "Study Program for Development of Information for Use of Vollenweider-OECD Eutrophication Modeling in Water Quality Management for Lakes and Reservoirs," Report of G. Fred Lee \& Associates, El Macero, CA, 22pp.

Lee, G. F. and Jones-Lee, A. (1995) (1996) "Appropriate Use of Numeric Chemical Water Quality Criteria," Health and Ecological Risk Assessment, 1:5-11 and Letter to the Editor, Supplemental Discussion, 2:233-234.

Lee, G. F. and Jones-Lee, A. (1998) "Determination of Nutrient Limiting Maximum Algal Biomass in Waterbodies," G. Fred Lee \& Associates, El Macero, CA.

Lee, G. F. and Jones-Lee, A. (2000) "Issues in Developing the San Joaquin River Deep Water Ship Channel DO TMDL," Report to Central Valley Regional Water Quality Control Board, Sacramento, CA.

Lee, G. F. and Jones-Lee, A. (2001a) "Issues in Managing the Water Quality Impacts of Phosphorus in Runoff from Agricultural Lands," Proceedings of American Chemical Society Agro Division Symposium, "Environmental Impact of Fertilizer Products in Soil, Air and Water," Chicago, IL, August) to be published by the American Chemical Society.

Lee, G. F. and Jones-Lee, A., (2001b) "Issues in Developing the San Joaquin River, CA, DO TMDL: Balancing Point and Nonpoint Oxygen Demand/Nutrient Control," Proceedings of the WEF and ASIWPCA TMDL Science Conference, St. Louis, MO,

Lee, G. F. and Jones-Lee, A. (2002) "Synthesis of Findings on the Causes and Factors Influencing Low DO in the San Joaquin River Deep Water Ship Channel Near Stockton, CA," Report Submitted to SJR DO TMDL Steering Committee/Technical Advisory Committee and CALFED Bay-Delta Program, G. Fred Lee \& Associates, El Macero, CA, May.

Lee, G. F., Jones-Lee, A., and Rast, W. (1995a) "Secchi Depth as a Water Quality Parameter," Report of G. Fred Lee \& Associates, El Macero, CA.

Lee, G. F.; Jones-Lee, A. and Rast, W. (1995b). "Alternative Approaches for Trophic State Classification for Water Quality Management, Part I: Suitability of Existing Trophic State Classification Systems," Report of G. Fred Lee \& Associates, El Macero, CA.

Lee, G. F.; Jones-Lee, A. and Rast, W. (1995c). "Alternative Approaches for Trophic State Classification for Water Quality Management, Part II: Application of Vollenweider-OECD Eutrophication Modeling Approach," Report of G. Fred Lee \& Associates, El Macero, CA. 
Lee, G. F.; Jones, R. A. and Rast, W. (1980) “Availability of Phosphorus to Phytoplankton and its Implication for Phosphorus Management Strategies," In: Phosphorus Management Strategies for Lakes, Ann Arbor Press, Ann Arbor, MI, pp 259-308.

OECD. (1982) "Eutrophication of Waters, Monitoring, Assessment, and Control," Organization for Economic Cooperation and Development, Paris.

Rast, W. and Lee, G. F. (1978) "Summary Analysis of the North American (US Portion) OECD Eutrophication Project: Nutrient Loading-Lake Response Relationships and Trophic State Indices," US Environmental Protection Agency, EPA 600/3-78-008, Corvallis, OR.

Rast, W. and Lee, G. F. (1983) "Nutrient Loading Estimates for Lakes," J. Env. Eng., 109:502517.

Rast, W., Jones, R. A. and Lee, G. F. (1983). "Predictive Capability of US OECD Phosphorus Loading-Eutrophication Response Models,” Journ. Water Pollut. Control Fed., 55:990-1003.

Richards, F. A. (1965) "Anoxic Basins and Fjords," in Chemical Oceanography, Riley and Skirrow, eds., Academic Press, New York, NY.

Sonzogni, W. C., Uttormark, P. C. and Lee, G. F. (1976) "A Phosphorus Residence Time Model: Theory and Application," Water Res. 10:429-435.

US EPA. (1998) "National Strategy for the Development of Regional Nutrient Criteria", US Environmental Protection Agency, Office of Water, EPA 822-R-98-002.

US EPA. (1999) "Protocol for Developing Nutrient TMDLs," US Environmental Protection Agency, Office of Water, EPA 841-B-99-007.

US EPA (2000a) "National Water Quality Inventory," US Environmental Protection Agency, Office of Water, EPA841-R-00-001.

US EPA (2000b) "Nutrient Criteria Technical Guidance Manual, Lakes and Reservoirs," US Environmental Protection Agency, Office of Water, EPA-822-B00-001.

US EPA. (2000c) "Nutrient Criteria Technical Guidance Manual, Rivers and Streams," US Environmental Protection Agency, Office of water, EPA-822-B-00-002.

Vollenweider, R. A. (1976) "Advances in Defining Critical Loading Levels for Phosphorus in Lake Eutrophication,” Mem. Ist. Ital. Idrobiol., 33:53-83.

Many of the author's papers and reports cited above are available from www.gfredlee.com. 